\title{
STUDY OF BACKGROUND PULSE SPECTRUM OF AN LSC SYSTEM
}

\author{
SIGURĐUR A EINARSSON and PÁLL THEODÓRSSON \\ Science Institute, University of Iceland \\ Dunhaga 3, IS-107 Reykjavík, Iceland
}

\begin{abstract}
Important advances have been made in reducing the background counting rate of gas proportional counters for ${ }^{14} \mathrm{C}$ dating through detailed and systematic study of the background components. Until recently, limited work has been reported on the study of the background of liquid scintillation counters (LSC). During the last few years, commercial systems with greatly reduced background have been introduced. It is shown that the best gas proportional counters and LSC have similar backgrounds for the same amount of sample material. Similar results with less effort may be expected with more detailed and fundamental knowledge of the components of the background of LSC. We report the results of a study of one photomultiplier LSC system where we research all parameters of importance: light collection efficiency, absorbed energy per photo-electron, pulse height spectrum and background counting rate.
\end{abstract}

\section{INTRODUCTION}

Liquid scintillation counting (LSC) has been used for ${ }^{14} \mathrm{C}$ dating for some 20 years. In this work, the background of the counting system should be as low as possible without sacrificing much in counting efficiency. The background of LS counters has, until recently, been rather high as compared to gas proportional counters.

Proportional counting for ${ }^{14} \mathrm{C}$ dating was developed in universities and research establishments where a continuous effort has been made to refine the technique, especially to lower the background. The development of LSC, on the other hand, was mainly in the hands of commercial firms and the systems were designed for general tracer work where low background was seldom important. This has brought us counting systems of high technical quality at a reasonable price with backgrounds acceptable even for dating. Presently, about half the ${ }^{14} \mathrm{C}$ determinations are done with commercial LSC that are mostly used with only minor modifications.

In the first decade after LSC was introduced to dating, limited effort was made to decrease background along lines that have brought such good results with gas counting systems. Noakes, Neary and Spaulding (1973) probably made the first low-level LSC system in 1972, which was designed for tritium. Noakes applied quite an advanced technique, as he used a large $\mathrm{NaI}$ crystal as a guard detector and a heavy lead shield. He got good results, as the guard detector reduced the background counting rate by $82 \%$. Two years later, Punning and Rajamae (1977) published the first results with an LSC as a guard detector. Punning tried both the conventional coincidence system with two photomultiplier tubes (PMT) as well as a single phototube system; the results were, however, not very promising.

Following this early start, the development of low-level LSC systems was slow. Noakes (1983) reported that a literature search had brought him only five articles on low-level LSC for the preceding eight years. The LSC conference in Banff showed, however, an increasing interest in the method. 
Polach et al $(1983 \mathrm{a}, \mathrm{b}, \mathrm{c})$ reported on the background of LSC systems, and Han-ying et al (1983) Pei-yun and Ting-kui (1983) described two Chinese systems, one using only a single phototube. A year later, a Finish firm, Wallac, presented the Quantulus, a new low-level LSC system that represented a leap forward in the technique. Somewhat later, Packard introduced a much simpler system with reduced background compared to conventional systems.

Despite this impressive progress, our knowledge of the source of background of LSC systems is still unsatisfactory, at least as compared to background of gas proportional counters. This can partly be explained by the fact that the process from primary ionization to the electrical pulse is more complicated in an LSC than in a proportional counter. In LSC, parameters describing the process are difficult to measure and the source of background has an additional component (Cerenkov radiation). It seems clear that a more fundamental approach is needed to study the background of LSC systems.

In this work we should be guided by extensive investigations of the source of background of gas counters. The laboratory at the University of Bern is an example of a good low-level laboratory where various gas counters, under varying conditions, have been used in a systematic study of background. The basement laboratory (there is another one deep underground) has ca $7 \mathrm{~m}$ water equivalent shielding above.

The background pulses of gas counters originate from: 1) the counter wall, either due to contamination or electrons released by $\gamma$-rays, or 2) the counting gas due to electrons released by $\gamma$-rays (Loosli, Heimann \& Oeschger, 1980). For 1), which dominates in gas counting systems below $3 \mathrm{~atm}$, Loosli gives $4 \cdot 10^{-4} \mathrm{cpm} / \mathrm{cm}^{2}$, and for 2) he gives $0.054 \mathrm{cpm} / \mathrm{g}$ for the surface laboratory.

In comparison with proportional counters, 1) is small in LSC and can practically be eliminated by selecting a teflon vial that is free from radioactive impurities; 2) should be practically the same for LSC systems as for proportional counters per weight of sample and the pulse height spectrum should also be similar. In addition to the above components, Cerenkov pulses contribute to the background of LSC.

In LSC, we are more restricted in the selection of materials for the detecting system, ie, the PMT, its magnetic shield and socket. The glass in the PMT always has some potassium with its radioactive ${ }^{40} \mathrm{~K}$ isotope. To reduce this, tubes with quartz windows are generally used, but the glass used in the graded seal between the quartz and borosilicate glass, that forms the rest of the envelope, will contain some potassium.

The lowest background reported with an LSC is for a Quantulus situated in a special laboratory where the gamma flux was reduced to 1/20 of the flux of an ordinary laboratory by selecting the construction materials of the room (Kojola et al, 1985). The background was $0.17 \mathrm{cpm}$ for $3 \mathrm{ml}$ of benzene. It is of interest to compare this to what could be expected if we assume contributions to the background from 2) only. Using the Bern value of $0.054 \mathrm{cpm} / \mathrm{g}$, we would expect a background counting rate of $0.13 \mathrm{cpm}$ for a sample of $3 \mathrm{ml}$ benzene $(2.43 \mathrm{~g})$. This shows that the background of the best LSC is comparable to the best gas proportional counters. 
Despite the high standard that has been obtained in low-level LSC systems, it seems likely that still better or similar results may be obtained with less effort. Thus, we initiated a project at the Science Institute of the University of Iceland to study various parameters of LSC systems with emphasis on background. We started with a single photomultiplier tube system and focused on the most common sample size in LSC dating, $3 \mathrm{ml}$ benzene.

PMTs, 2" in diameter, are used almost universally in LSC systems. Because small sample volume and close coupling between sample vial and tube would be used, a PMT with a smaller diameter seemed more desirable, as the smaller tube would presumably lead to lower background. A $11 / 8$ " tube was selected for the first phase of this work, and it has been used in all measurements reported here. We also intend to test 2" tubes and then a two-tube (coincidence) system.

\section{EXPERIMENTAL SETUP}

Figure 1 shows the photomultiplier tube with passive and active guards. The PMT is enclosed in a protective cylinder which is clamped in an upright position in a plexiglass stand. This allows the sample vial to be easily placed

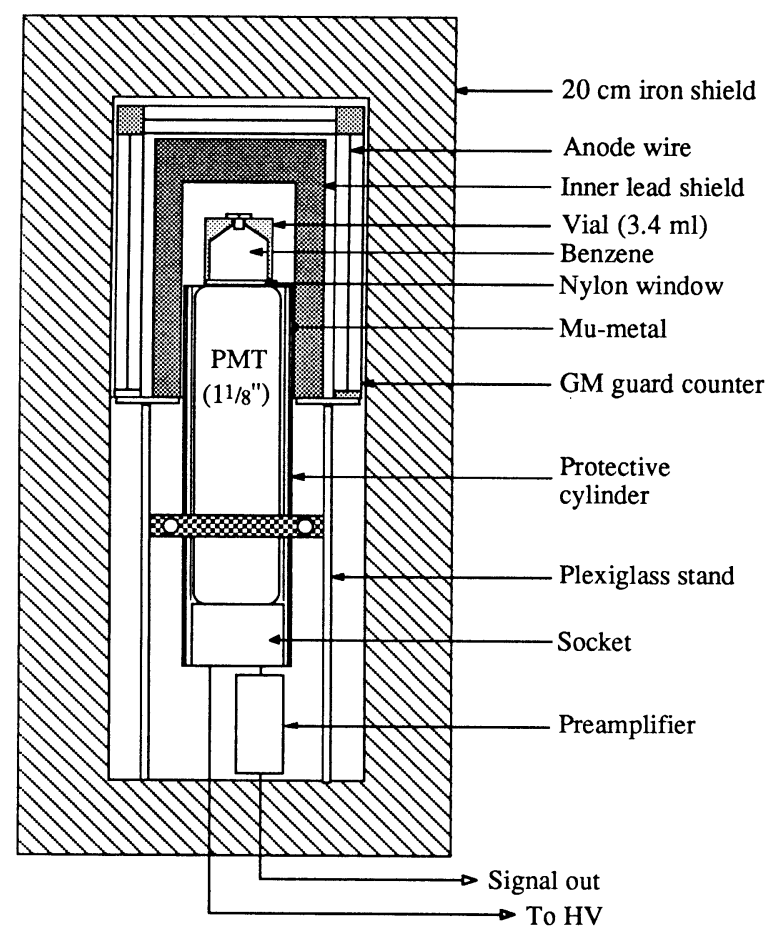

Fig 1. Schematic drawing of experimental setup (relative dimensions not to scale) 
on top of the PMT window. An inner lead shield, $1.5 \mathrm{~cm}$ thick, can be placed over the vial. The active guard covers the inner shield. Surrounding this is a $20 \mathrm{~cm}$ iron shield.

A Thorn EMI 1 1/8" 9924QA bialkaly phototube was used. A $\mu$-metal cylinder shields the tube from external electromagnetic fields. The passive inner shield is made of low-activity lead from the Boliden mine in Sweden and is hat-shaped to cover the vial and the top part of the PMT. The Geiger guard counter was specially made for this system with most of its enclosed hat-shaped volume active apart from small plexiglass spacers used for structural strength and anode wire support.

The signal from the PMT is analyzed and recorded by the equipment shown in Figure 2. The preamplifier is charge-sensitive and the main linear

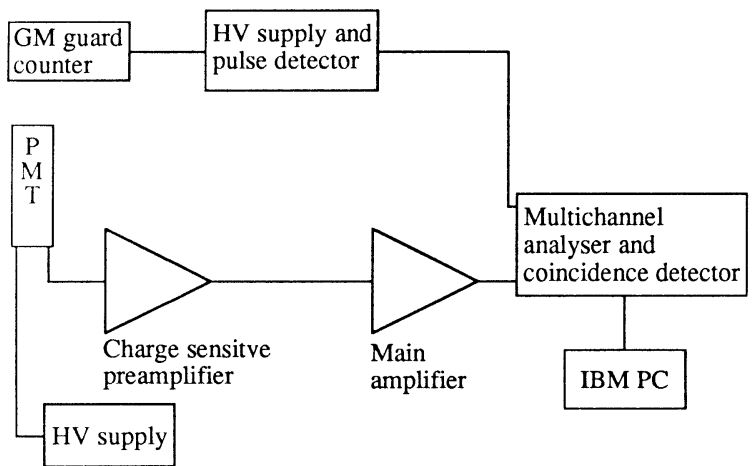

Fig 2. Block diagram of signal processing and recording equipment

amplifier has a $2 \mu$ s shaping constant. The amplified pulses are recorded by a $2 \times 256$ channel pulse height analyzer. Pulses from the guard counter split the spectrum into coincidence and anticoincidence spectra (256 channels each). Collected data can be transmitted on command to an IBM PC computer for pulse spectrum display and analysis.

Four vial materials were tested: aluminium, copper, brass and nylon. The window material in all cases was nylon. The size of the vial chamber was designed to hold ca $3 \mathrm{~g}$ of scintillator solution $(3.4 \mathrm{ml})$. The aluminium vial was polished to improve its reflectivity. The copper and brass vials were coated with silver, which was electrically deposited, to obtain better reflecting properties. The surface of the nylon vial was made reflective by gluing an aluminized mylar foil to its outer surface.

A solution of $1.7 \%$ butyl PBD and $0.01 \%$ POPOP in benzene was used in the measurements. Butyl PBD with POPOP was found to be superior to butyl PBD alone as a marked improvement in light output was then obtained. This indicates that spectral matching was improved for this PMT on adding the wave-length shifter. The activity of the ${ }^{14} \mathrm{C}$ standard scintillator solution was $8.73 \mathrm{dpm} / \mathrm{ml}$. 


\section{ENERGY CALIBRATIONS}

It is important to maximize the pulse height for a given energy deposited in the scintillator. This property is measured by the index of merit, $\eta$ (Coursey \& Mann, 1980), the number of electrons released from the photocathode $/ \mathrm{keV}$ absorbed in the scintillator. This parameter is easily measured in our system and was used to select the most suitable vial, scintillator solution and light coupling. $\eta$ was repeatedly measured for the grease-coupled nylon vial to check the stability of the system (see Table 2 ).

The index of merit, $\eta$ (Coursey \& Mann, 1980) is described by:

$$
\eta=\mathrm{S}_{\mathrm{x}} \cdot \mathrm{G} \cdot \mathrm{C}_{\mathrm{pt}} / \mathrm{E}_{\mathrm{a}}
$$

where $S_{x}=$ scintillation efficiency, $G=$ light collection efficiency, $C_{p t}=$ phototube response factor and $\mathrm{E}_{\mathrm{a}}=$ energy absorbed in scintillator. Benzene was chosen due to its relevance to ${ }^{14} \mathrm{C}$ dating although better solvents are available, such as toluene.

The user has limited possibilities to influence the performance of the PMT. It is possible to optimize spectral matching and electron collection at the first dynode. Further, it is possible to select a tube with the least possible natural radioactive material. The light collection efficiency, or the $\mathrm{G}$ factor, can be optimized by the designer to a considerable extent. In the literature, only rough estimates are to be found for this important parameter.

It is to be expected that a higher light collection efficiency can be obtained with 1 PMT than in a 2-PMT system due to simpler geometry. It is important to get as much of the scintillation photons onto the cathode surface, but even more so for a 1-PMT system, because of the way noise reduction is obtained in each system. In a 2-lamp system, much of the background can be reduced by counting only coincidences, thus eliminating thermal electrons emitted from the photocathode. Cerenkov radiation can also be reduced by reducing crosstalk between the PMT scintillator pulses. In the 1-PMT system, other methods are used and here, efficient light collection helps to raise the signal above the background pulses of the PMT. As little light as possible must be allowed to escape or be absorbed. The photon path lengths must also be kept short and good coupling ensured between the PMT and the vial window.

Energy calibration measurements were used to determine the index of merit, $\eta$, for vials made from the four materials mentioned. Silicone grease light coupling between vial and PMT was used to enhance light collection. We also tried to measure the absolute light collection efficiency of the system by placing the nylon vial, with the window removed, onto the surface of the PMT window. We formed a seal by pressing the vial onto the glass surface with a specially designed clamping device obtaining direct contact between the liquid and tube face, and minimizing interface losses.

Three radioisotopes were used externally: ${ }^{125} \mathrm{I}(27.5 \mathrm{keV}),{ }^{241} \mathrm{Am}(60$ $\mathrm{keV}$ ) and ${ }^{133} \mathrm{Ba}$ (Compton edge at $207 \mathrm{keV}$ ). Figure 3A shows a typical energy spectrum for ${ }^{133} \mathrm{Ba}$ and Figure $3 \mathrm{~B}$ the 1-photoelectron peak of the tube from thermal emission. The values of $\eta$ calculated from the calibration data (Table 1) clearly indicate that the number of photoelectrons per keV 
TABLE 1

$\eta$ for vials and light coupling

\begin{tabular}{llcccc}
\hline \multirow{2}{*}{ Vial/reflector } & Coupling & \multicolumn{2}{c}{$\eta$ (photoelectrons / keV) } & & \\
\cline { 3 - 6 } & & $\begin{array}{c}{ }^{125} \mathrm{I} \\
(27.5 \mathrm{keV})\end{array}$ & $\begin{array}{c}{ }^{241} \mathrm{Am} \\
(60 \mathrm{keV})\end{array}$ & $\begin{array}{c}{ }^{133} \mathrm{Ba} \\
(207 \mathrm{keV})\end{array}$ & $\begin{array}{c}\text { Absolute } \% \\
\left(\text { for }{ }^{133} \mathrm{Ba}\right)\end{array}$ \\
\hline Aluminium & Silicone grease & 0.53 & 0.54 & - & $50.5^{*}$ \\
Brass/silver & Silicone grease & 0.46 & - & 0.53 & 46.9 \\
Copper/silver & Silicone grease & 0.52 & 0.55 & 0.60 & 53.1 \\
Nylon/Al foil & Silicone grease & 0.90 & 0.92 & 1.00 & 88.5 \\
Nylon/Al foil & No grease & 0.66 & 0.71 & 0.79 & 69.9 \\
Nylon/Al foil & Direct contact & 1.01 & 1.07 & 1.13 & 100.0 \\
\hline${ }^{*}$ For ${ }^{241} \mathrm{Am}$ & & & & &
\end{tabular}

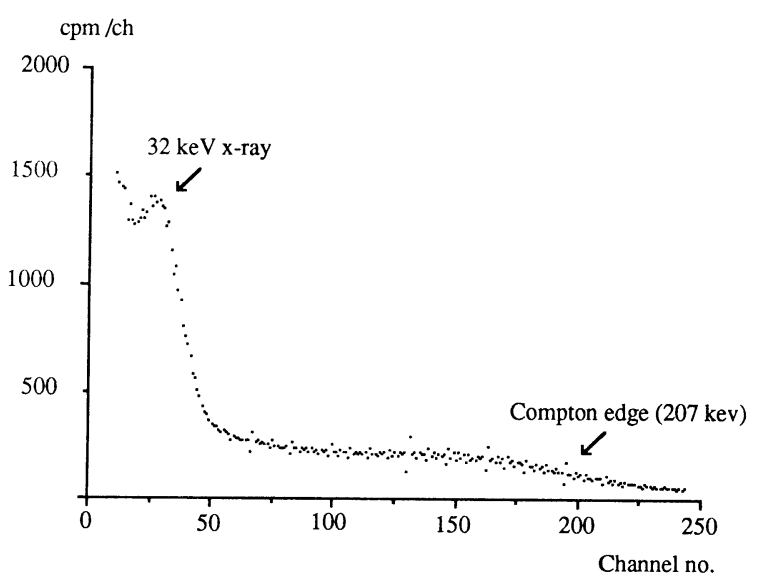

Fig 3A. The spectrum of Ba 133 (0.6 times normal counting gain)

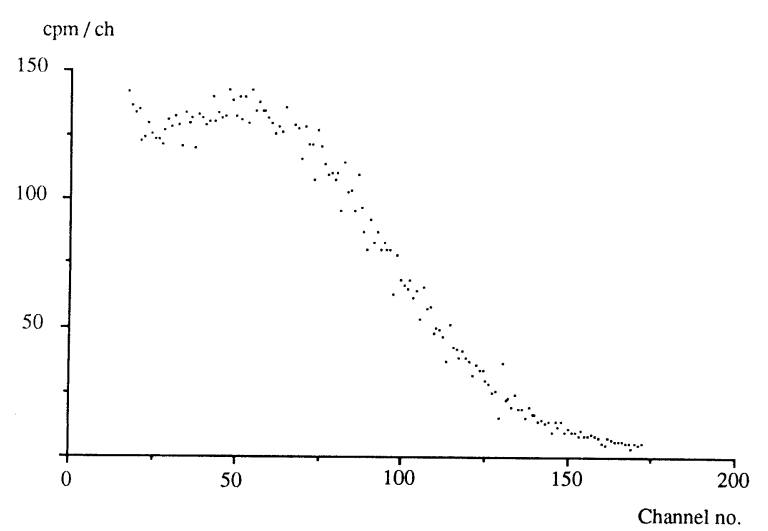

Fig 3B. One photoelectron peak due to thermal emission in the phototube (32 times normal counting gain) 
decreases with radiation energy, which agrees with Horrocks ${ }^{-}$(1964). Assuming that $100 \%$ light collection efficiency is obtained by direct coupling of the scintillator to the PMT window, we can find the efficiency of other configurations. Light collection from aluminium, brass and copper vials are similar, but the aluminized mylar foil reflector and silicone grease coupling of the nylon vial are clearly superior. Without grease coupling, the nylon vial shows reduced light efficiency, but is still higher than the silvercoated brass and copper vials.

TABLE 2

Index of merit for the grease-coupled nylon vial with standard deviation

\begin{tabular}{ccc}
\hline $\begin{array}{c}\text { Source energy } \\
(\mathrm{keV})\end{array}$ & $\begin{array}{c}\eta \\
\mathrm{e} / \mathrm{keV}\end{array}$ & $\sigma \%$ \\
\hline 207 & 1.01 & 4.0 \\
60 & 0.92 & 4.3 \\
27.5 & 0.90 & 3.3 \\
\hline
\end{tabular}

Table 2 shows the result of repeated measurements of the index of merit for the grease-coupled nylon vial. The error $(1 \sigma)$ is ca $4 \%$ for all energies, indicating that the system remains stable within acceptable limits. The system was dissembled and reassembled several times during the measurements which did not seem to have any effect on the system reproducibility.

\section{Discussion of Energy Calibrations}

We get a maximum index of merit of 1.13 photoelectrons $/ \mathrm{keV}$ (Table 1). According to Birks (1974), a liquid scintillator at ambient temperature in contact with air contains ca $2 \times 10^{-3} \mathrm{M}$ of absorbed $\mathrm{O}_{2}$ which reduces the scintillation yield by ca $20 \%$. Replacing the benzene with toluene gives a $30 \%$ better scintillation yield (Birks, 1974), and with argon flushing to remove oxygen, should increase the scintillation yield by nearly $50 \%$. We should expect a $50 \%$ increase in light-collection efficiency, with an index of merit near 1.7 photoelectrons $/ \mathrm{keV}$. This agrees well with Horrocks' (1964) results. It will be interesting to extend this method to a 2-PMT system.

\section{BACKGROUND MEASUREMENTS}

As described above, the two main contributions to background in LSC systems are $\gamma$-induced electrons in the liquid and vial walls and Cerenkov pulses due to cosmic muons and radioactive impurities in the PMT. The muon-induced Cerenkov contribution is small. The contribution from radioactive impurities is presumably small as the PMT is selected for low ${ }^{40} \mathrm{~K}$ activity. Accordingly, the largest contribution comes from secondary radiation generated in the shield by the hard component of the cosmic radiation. Most of the environmental $\gamma$ is removed by the passive shield, leaving secondary $\gamma$ from the cosmic muons, which escape the active guard, and $\gamma$ from impurities in the shield material. Thus, the background depends largely on the efficiency of the active shield in removing the cosmic contribution, assuming shield materials near the detector are relatively free of impurities. 
Figure 1 shows our setup for background and ${ }^{14} \mathrm{C}$ measurements. Measurements for further reduction of background were made at a depth of $38 \mathrm{~m}$ in a hydroelectric power plant at Írafoss near Thingvellir with practically the same setup. Measurements were made on the surface inside the station house and in the water exit tunnel. For each set of background and ${ }^{14} \mathrm{C}$ measurements, data was collected over a $3000-4000 \mathrm{~min}$ period. Before and after each run light collection efficiency was measured to ensure that the system had remained stable. Figure 4 shows typical total counts and coincidence background spectra, normalized to $1000 \mathrm{~min}$.

The most relevant parameter in comparing low-level counting systems is the factor of merit (Polach, 1978):

$$
\mathrm{fM}=\mathrm{s} / \sqrt{\mathrm{B}}
$$

where $\mathrm{S}$ is the measured net count rate converted to $95 \%$ oxalic acid standard and B is the background. The counting efficiency, E, is also needed to evaluate an LSC system. Table 3 shows counting efficiency,

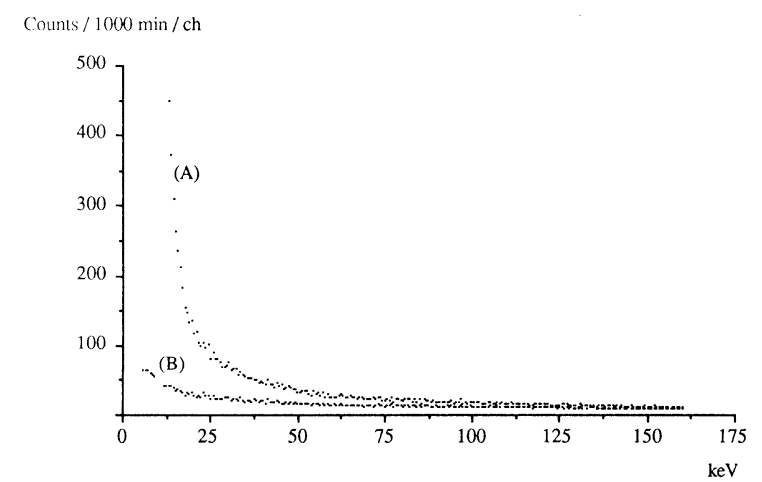

Fig 4. A. Total background specrum; B. Coincidence background spectrum

TABLE 3

Background and ${ }^{14} \mathrm{C}$ measurements

Total $\left(\mathrm{B}_{\text {tot }}\right)$ and anticoincidence $\left(\mathrm{B}_{\mathrm{ac}}\right)$ background counts

\begin{tabular}{|c|c|c|c|c|c|c|c|c|}
\hline \multirow{2}{*}{$\begin{array}{l}\text { Discrimi- } \\
\text { nation } \\
\text { levels }(\mathrm{keV})\end{array}$} & \multicolumn{3}{|c|}{$\begin{array}{c}\text { In the } \\
\text { laboratory }\end{array}$} & \multicolumn{2}{|c|}{$\begin{array}{l}\text { Surface at } \\
\text { Írafoss }\end{array}$} & \multicolumn{2}{|c|}{$\begin{array}{c}38 \mathrm{~m} \text { below } \\
\text { ground at Irafoss }\end{array}$} & \multirow[b]{2}{*}{$\begin{array}{l}\mathrm{E} \\
\%\end{array}$} \\
\hline & $\begin{array}{c}\mathrm{S} \\
\mathrm{cpm}\end{array}$ & $\begin{array}{l}\mathrm{B}_{\text {tot }} \\
\mathrm{cpm}\end{array}$ & $\begin{array}{l}\mathrm{B}_{\mathrm{ac}} \\
\mathrm{cpm}\end{array}$ & $\begin{array}{l}\mathrm{B}_{\text {tot }} \\
\mathrm{cpm}\end{array}$ & $\begin{array}{l}\mathrm{B}_{\mathrm{ac}} \\
\mathrm{cpm}\end{array}$ & $\begin{array}{l}\mathrm{B}_{\text {tot }} \\
\mathrm{cpm}\end{array}$ & $\begin{array}{l}\mathrm{B}_{\mathrm{ac}} \\
\mathrm{cpm}\end{array}$ & \\
\hline $15-156$ & 27.6 & 5.7 & 4.4 & 6.9 & 5.1 & 2.6 & 2.5 & 73.4 \\
\hline $20-156$ & 25.6 & 4.3 & 3.2 & 4.9 & 3.2 & 1.6 & 1.5 & 68.1 \\
\hline $25-156$ & 24.0 & 3.6 & 2.6 & 3.9 & 2.5 & 1.2 & 1.1 & 63.7 \\
\hline $30-156$ & 21.9 & 3.0 & 2.2 & 3.4 & 2.1 & 0.9 & 0.8 & 58.3 \\
\hline $35-156$ & 20.3 & 2.6 & 1.9 & 3.0 & 1.7 & 0.7 & 0.6 & 54.1 \\
\hline
\end{tabular}


measured background and converted count rate for the ${ }^{14} \mathrm{C}$ standard. The vial contains $3.01 \mathrm{~g}(3.42 \mathrm{ml})$.

\section{Discussion of Background Measurements}

Taking the LS system $38 \mathrm{~m}$ underground is equivalent to an absorbing layer of ca $100 \mathrm{~m}$ water equivalent. This should reduce the muon flux by a factor of 18 (George, 1957). At this depth, the background in the 30$156 \mathrm{keV}$ interval is reduced from a total count rate of $3.4 \mathrm{cpm}$ at ground level to $0.9 \mathrm{cpm}$, a $73 \%$ reduction, and the factor of merit increases from 12.6 to 23.1. The anticoincidence background count rate is $0.8 \mathrm{cpm}$ in the same interval, a $75 \%$ reduction, and the factor of merit increases from 14.8 to 24.5. This result is promising as further improvements should be possible with a better and more effective guard counter and with a thicker inner lead shield.

Other possibilities exist for reducing the background somewhat further, including selection of PMT and a more careful selection of materials close to the detector. The smaller $11 / 8^{\prime \prime}$ tubes have not been optimized to LSC requirements to the same degree as $2^{\prime \prime}$ tubes. Consequently, the second phase of this project will focus on $2^{\prime \prime}$ PMTs.

\section{CONCLUSION}

The first phase of this study of LS counters included background count rates as well as all important parameters. Results are promising and have brought us closer to understanding the background counting rates of LSC, which will form the basis for future research. Our work on single PMT systems will be followed by similar studies on 2-PMT coincidence systems.

\section{REFERENCES}

Birks, J B, 1974, Towards an understanding of the scintillation process in organic molecular systems, in Stanley, P E and Scoggins, B A, eds, Liquid scintillation counting, recent developments: London, Academic Press, p 1-38.

Coursey, B M and Mann, W B, 1980, Design of high-efficiency liquid-scintillation counting systems, in Taylor, J G V and Mann, W B, eds, The application of liquid-scintillation counting to radionuclide metrology: Sevres, Bur Internatl Poids et Mesures, p 23-35.

George, E P, 1957, Observations of cosmic rays underground and their interpretation, in Wilson, J G, ed, Progress in cosmic ray physics: Amsterdam, North Holland Publishing
Co, p 395-451.

Han-ying, J, Shao-wan, L, Shi-mi, F, Wen-xin, Z, Ting-kui, Z, Yuan-zhen, Y, Mei-fen, L, Peiyun, F, Shu-xian, W, Cheng-hang, P and Pei-dong, J, 1983, Model DYS low-level liquid scintillation counter, in McQuarrie, S A, Ediss, C, Wiebe, L I, eds, Advances in scintillation counting: Banff, Univ Alberta Press, p 478-493.

Horrocks, D L, 1964, Pulse height-energy relationship of a liquid scintillator for electrons of energy less than $100 \mathrm{keV}$ : Nuclear Instruments \& Methods, v 27, p 253-258.

Kojola, H, Polach, H, Murmi, J, Heinonen, A, Oikari, T and Soini, E, (ms) 1985, Low level liquid scintillation spectrometer for $\beta$-counting: Preprint, Nordic conf on applications of sci methods in archaeometry, ISKOS, 3rd.

Loosli, H H, Heimann, M and Oeschger, H, 1980, Low-level gas proportional counting in an underground laboratory, in Stuiver, $\mathrm{M}$ and $\mathrm{Kra}, \mathrm{R} \mathrm{S}$, eds, International ${ }^{14} \mathrm{C}$ conf, 10 th, Proc: Radiocarbon, v 22, no. 2, p 461-469. 
Noakes, J E, 1983, Applications of low-level liquid scintillation counting, in McQuarrie, S A Ediss, C, Wiebe, L I, eds, Advances in scintillation counting: Banff, Univ Alberta Press, p 407-419.

Noakes, J E, Neary, M P and Spaulding, J D, 1973, Tritium measurements with a new liquid scintillation counter: Nuclear Instruments Methods, v 109, p 177-187.

Pei-yun, F and Ting-kui, Z, 1983, A single photomultiplier liquid scintillation counting apparatus for ${ }^{14} \mathrm{C}$ low-level measurement, in McQuarrie, S A, Ediss, C, Wiebe, L I, eds, Advances in scintillation counting: Banff, Univ Alberta Press, p 456-467.

Polach, H A, 1987, Evaluation and status of liquid scintillation counting for radio carbon dating: Radiocarbon, v. 29, no. 1, p 1-11.

Polach, H, Gower, J, Kojola, H and Heinonen, A, 1983a, An ideal vial and cocktail for lowlevel scintillation counting, in McQuarrie, S A, Ediss, C, Wiebe, L I, eds, Advances in scintillation counting: Banff, Univ Alberta press, p 508-525.

Polach, H, Nurmi, J, Kojola, H and Soini, E, 1983b, Electronic optimization of scintillation counters for detection of low-level ${ }^{3} \mathrm{H}$ and ${ }^{14} \mathrm{C}$, in McQuarrie, S A, Ediss, C, Wiebe, L I, eds, Advances in scintillation counting: Banff, Univ Alberta Press, p 420-441.

Polach, H, Robertson, S, Butterfield, D, Gower, J and Soini, E, 1983c, The 'windowless' approach to scintillation counting: Low-level ${ }^{14} \mathrm{C}$ as an example, in McQuarrie, S A, Ediss, C, Wiebe, L I, eds, Advances in scintillation counting: Banff, Univ Alberta Press, p 494 507.

Punning, J M and Rajamae, R, 1977, Some possibilities for decreasing the background of liquid scintillation beta-ray counter, in Povinec, P and Usacev, S, Proc, Internatl conf on low - radioactivity measurements and application: Slovenské Pedagogické Nakladatelstvo, Bratislava, p 169-171. 